\title{
Jules Michelet, Correspondance générale
}

\section{Lise Sabourin}

\section{(2) OpenEdition}

\section{Journals}

\section{Édition électronique}

URL : http://journals.openedition.org/studifrancesi/34853

DOI : $10.4000 /$ studifrancesi.34853

ISSN : 2427-5856

\section{Éditeur}

Rosenberg \& Sellier

\section{Édition imprimée}

Date de publication : 1 novembre 2005

Pagination : 430

ISSN : 0039-2944

\section{Référence électronique}

Lise Sabourin, « Jules Michelet, Correspondance générale », Studi Francesi [En ligne], 146 (XLIX | II) | 2005, mis en ligne le 30 novembre 2015, consulté le 20 avril 2021. URL : http://

journals.openedition.org/studifrancesi/34853; DOI : https://doi.org/10.4000/studifrancesi.34853

Ce document a été généré automatiquement le 20 avril 2021.

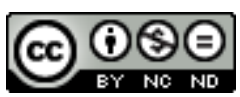

Studi Francesi è distribuita con Licenza Creative Commons Attribuzione - Non commerciale - Non opere derivate 4.0 Internazionale. 


\title{
Jules Michelet, Correspondance générale
}

\author{
Lise Sabourin
}

\section{RÉFÉRENCE}

JULES MICHELET, Correspondance générale, 1862-1865 (t. X), 1866-1870 (t. XI), 1871-1874 et suppléments (t. XII), textes réunis, classés et annotés par LOUIS LE GUILLOU, Paris, Honoré Champion, 1999, 2000, 2001, pp. 955, 907 et 1051.

1 Ces trois derniers volumes de la Correspondance de Michelet présentent, comme les précédents, index des noms cités, index sommaire des lieux et index des correspondants, avec une table des lettres indiquant noms et dates. L'annotation reste rare, mais l'apport essentiel pour la connaissance des ultimes années.

2 Le t. X montre bien l'anticléricalisme devenu radical de Michelet occupé à rédiger son Histoire de France de Louis XIV, avec la révocation de l'édit de Nantes et les dragonnades, à la Régence; La Sorcière et La Bible de l'humanité publiées en 1862-63 et 1864 se ressentent aussi de ce «mal à l'histoire» que viennent de surcroît exacerber la louange, dénoncée par héritage voltairien, de Mgr Myriel dans Les Misérables et, plus intimement, le décès de son fils Charles, enterré à sa demande selon le rite catholique. La santé de l'écrivain décline, sans empêcher pourtant la poursuite obstinée de son travail, visible en des pages éblouissantes quoique tendancieuses, qui tendent à démontrer un obscurantisme égyptien et judéo-chrétien par contraste avec l'illumination grecque, persane et indienne.

3 Sa femme Athénaïs, dont le t. XI apporte judicieusement plusieurs dizaines de lettres retrouvées parmi des milliers écrites, se charge de plus en plus durant les années 1866-1870 des contrats avec les éditeurs, des réponses aux correspondants de son mari, fournissant ainsi de précieux éclairages sur la rédaction du XVII ${ }^{\mathrm{e}}$ tome de l'Histoire de France, de La France devant l'Europe, tout en publiant elle-même ses Mémoires d'une enfant et organisant l'édition illustrée par Giacomelli de L'Oiseau. 
4 Enfin, après le désastre durement ressenti de la guerre de 1870 et ses conséquences nationales Michelet frappé d'apoplexie publie encore les trois premiers tomes de L'Histoire du XIX ${ }^{e}$ siècle, avant de s'éteindre le 9 février 1874. Louis Le Guillou sélectionne quelques-unes des lettres de condoléances reçues par sa veuve, notamment concernant les relations ultimes de l'historien avec Alfred Dumesnil, Eugène Noël et les époux Quinet (voir parallèlement la Correspondance d'Edgar Quinet éditée par Simone Bernard.Griffiths et Ceri Crossley).

5 L'intérêt de ce dernier tome réside surtout, avec l'index général des correspondants de toute l'édition, dans les suppléments nombreux que la durée d'une telle entreprise offre nécessairement: plus de 800 lettres complètent les années précédentes, comblant certaines lacunes antérieurement signalées, permettant des datations de missives, apportant des pièces capitales (telles les lettres à Guigniaut de Heidelberg le 20 août 1828, sur l'Angleterre à Mme Angelet du 14 août 1834 ou de Quinet le 22 janvier 1869).

6 Le lecteur dispose désormais d'une immense banque de données (12848 lettres) sur l'écrivain et son siècle. 